\title{
Spatial and temporal variations of aridity shape dung beetle assemblages towards the Sahara desert
}

\author{
Indradatta deCastro-Arrazola ${ }^{\text {Corresp.. }}{ }^{1,2}$, Joaquín Hortal ${ }^{1,3}$, Marco Moretti ${ }^{4}$, Francisco Sánchez-Piñero ${ }^{2}$ \\ 1 Department of Biogeography and Global Change, Museo Nacional de Ciencias Naturales (MNCN-CSIC), Madrid, Spain \\ 2 Departamento de Zoología, Facultad de Ciencias, Universidad de Granada, Granada, Spain \\ 3 Department of Ecology, Instituto de Ciências Biologicas, Universidade Federal de Goiás, Goiânia, Brazil \\ 4 Department of Biodiversity and Conservation Biology, Swiss Federal Research Institute WSL, Birmensdorf, Switzerland \\ Corresponding Author: Indradatta deCastro-Arrazola \\ Email address: indra@mncn.csic.es
}

Background. Assemblage responses to environmental gradients are key to understand the general principles behind the assembly and functioning of communities. The spatial and temporally uneven distribution of water availability in drylands creates strong aridity gradients. While the effects of spatial variations of aridity are relatively well known, the influence of the highly-unpredictable seasonal and interannual precipitations on dryland communities has been seldom addressed.

Aims. Here we study the seasonal and interannual responses of dung beetle (Coleoptera, Scarabaeidae) communities to the variations of water availability along an arid to semiarid region of the Mediterranean.

Methods. We surveyed a $400 \mathrm{~km}$ linear transect along a strong aridity gradient from the Mediterranean coast to the Sahara (Eastern Morocco), during four sampling campaigns: two in the wet season and two in the dry season. We measured richness, abundance and evenness. Variations in community composition between sites, seasons and years were assessed through beta diversity partitioning of dissimiliarity metrics based on species occurrences and abundances. The effects of climate, soil, vegetation and dung availability were evaluated using Spearman-Rank Correlations, GLMs and partial least-squares generalized lineal regressions for community structure, and NMDS, PERMANOVA and dbRDA-based variation partitioning for compositional variations.

Results. Dung beetle abundance and richness showed large seasonal variations, but remained relatively similar between years. Increasing aridity resulted in decreasing species richness and an ordered replacement of species, namely the substitution of the trophically diverse Mediterranean fauna by saprophagous and generalist species both in space towards the Sahara and seasonally in the dry season. Indeed, aridity and its interaction with season and year were the strongest correlates of variations in richness and composition.

Discussion. Our study shows that aridity determines composition in dung beetle communities, filtering species both in space and time. Besides the expected decrease in richness, such environmental filtering promotes a functional shift to generalist and saprophagous species in arid conditions, probably related to changes in resource quality along the transect and through the year. Our results highlight the importance of considering the effects of the highly-unpredictable seasonal and interannual variations in precipitation when studying dryland communities. 
1 Spatial and temporal variations of aridity shape dung beetle assemblages 2 towards the Sahara desert

3 Indradatta deCastro-Arrazola ${ }^{1,2}$, Joaquín Hortal ${ }^{1,3}$, Marco Moretti ${ }^{4}$, Francisco Sánchez-Piñero ${ }^{2}$

4 1. Department of Biogeography and Global Change, Museo Nacional de Ciencias Naturales 5 (MNCN-CSIC), C/José Gutierrez Abascal, 2, 28006 Madrid, Spain

6 2. Departamento de Zoología, Facultad de Ciencias, Universidad de Granada, Campus de 7 Fuentenueva, 18071 Granada, Spain

8 3. Department of Ecology, Instituto de Ciências Biologicas, Universidade Federal de Goiás, 9 74001-970 Goiânia, Brazil

10 4. Department of Biodiversity and Conservation Biology, Swiss Federal Research Institute WSL, 11 Zürcherstrasse 111, Birmensdorf, CH 8903, Switzerland

13 Corresponding Author:

14 Indradatta deCastro-Arrazola

15 Email address: indra@mncn.csic.es 


\section{ABSTRACT}

17 Background. Assemblage responses to environmental gradients are key to understand the general

18 principles behind the assembly and functioning of communities. The spatial and temporally uneven

19 distribution of water availability in drylands creates strong aridity gradients. However, the effects

20 of spatial variations of aridity on diversity remains unclear and the influence of the highly-

21 unpredictable seasonal and interannual precipitations on dryland communities has been seldom 22 addressed.

23 Aims. Here we study the seasonal and interannual responses of dung beetle (Coleoptera,

24 Scarabaeidae) communities to the variations of water availability along a semiarid to desert

25 transition of the Mediterranean region.

26 Methods. We surveyed a $400 \mathrm{~km}$ linear transect along a strong aridity gradient from the

27 Mediterranean coast to the Sahara (Eastern Morocco), during four sampling campaigns: two in the

28 wet season and two in the dry season. We measured richness, abundance and evenness. Variations

29 in community composition between sites, seasons and years were assessed through beta diversity

30 partitioning of dissimiliarity metrics based on species occurrences and abundances. The effects of

31 climate, soil, vegetation and dung availability were evaluated using Spearman-Rank Correlations,

32 GLMs and partial least-squares generalized lineal regressions for community structure, and

33 NMDS, PERMANOVA and dbRDA-based variation partitioning for compositional variations.

34 Results. Dung beetle abundance and richness showed large seasonal variations, but remained

35 relatively similar between years. Increasing aridity resulted in decreasing species richness and an

36 ordered replacement of species, namely the substitution of the trophically diverse Mediterranean

37 fauna by saprophagous and generalist species both in space towards the Sahara and seasonally in

38 the dry season. Indeed, aridity and its interaction with season and year were the strongest correlates 
39 of variations in richness and composition.

40 Discussion. Our study shows that aridity determines composition in dung beetle communities,

41 filtering species both in space and time. Besides the expected decrease in richness, such

42 environmental filtering promotes a functional shift to generalist and saprophagous species in arid

43 conditions, probably related to changes in resource quality along the transect and through the year.

44 Our results highlight the importance of considering the effects of the highly-unpredictable seasonal

45 and interannual variations in precipitation when studying dryland communities. 


\section{INTRODUCTION}

47 Understanding the processes behind the geographical patterns of diversity is one of the central questions of ecology. Spatial gradients have long served as natural experiments to understand general principles in the ecology of animals, through the study of how changes in environmental factors, such as climate, influence the ecological and evolutionary processes that determine

51 biodiversity variations from local to global scales (e.g. Pianka, 1966; Willig, Kaufman \& Stevens, 52 2003; Sanders \& Rahbek, 2012). Aridity gradients emphasizing changes in water availability, a

53 key abiotic factor, are especially important to understand geographical variations in biodiversity 54 in warm temperate and tropical systems (Hawkins et al., 2003; Hawkins \& Porter, 2003). However, 55 the effects of aridity on diversity remain unclear (Rohde, 1992; Willig et al., 2003) because the 56 response depends on taxa and geographic regions (Polis, 1991; Wiens, Kozak \& Silva, 2013). For example, scorpion and bird diversity increase with aridity in North America, but decrease in Australia (Polis 1991). On the contrary, in ants there is a negative relationship of aridity with diversity in North America but the relationship is positive in Australian deserts (Polis 1991) and there is no relationship in Australian Savannas (Andersen, Toro \& Parr, 2015). Understanding biodiversity patterns across aridity gradients is also relevant because drylands currently occupy more than $40 \%$ of the land on Earth and their extent is expected to increase in the next decades in response to climate change (Huang et al., 2016). received scarce attention (Bishop et al., 2014) despite their importance in shaping community assemblages and large-scale diversity patterns (Pianka, 1966; Willis \& Whittaker, 2002; White et al., 2010; Gouveia et al., 2013). However, both intra-annual (seasonality) and inter-annual 
69 of local species pools (Pianka, 1966; Tonkin et al., 2017). Temporal variations are particularly

70 important in Mediterranean (Agoglitta et al., 2012; Seager et al., 2014) and subtropical (Belda et

71 al., 2014) climates, where the spatially uneven distribution of water at fine and broad scales is

72 coupled with large variations in water availability within and between years (i.e. seasonal and

73 interannual variations).

Mediterranean areas typically host strong spatial gradients of water availability, often

75 ranging from warm-temperate to desert conditions (Safriel et al., 2018). Mediterranean climate is highly seasonal, with dry hot summers and wet cool winters that result in large differences in water availability throughout the year. Importantly, besides this overall seasonal regime, arid environments show large unpredictable variations in rainfall between seasons and years, that can sometimes be larger than the typical within-year fluctuations (Ward, 2009). These differences may result in differing diversity patterns between seasons, in particular along aridity gradients, where their extremes show distinct seasonal variations - from abundant rains in winter and scarce in summer at the more humid places to scarce rains throughout the year in the desert. Drylands respond differently to extreme precipitations and seasonal rainfall than mesic biomes, with highly variable and temporally-limited increases in plant productivity (Zeppel et al., 2014). Such extreme variations in water and resource availability drive the phenology of desert animals (Polis, 1991), and may produce strong oscillations in their communities (Tonkin et al., 2017). Despite the striking changes in community composition and structure caused by these variations in biologically available water (Seely \& Louw, 1980; Polis et al., 1997; Holmgren et al., 2001), the spatial and temporal effects of aridity on the diversity of invertebrates and trophic interactions have been seldom studied (Labidi, Errouissi \& Nouira, 2012; Tshikae, Davis \& Scholtz, 2013a).

Dung beetles of the family Scarabaeidae feed and nest on the faeces of diverse animals, 
92 especially mammalian herbivores, showing diverse dung-exploitation strategies (Hanski \&

93 Cambefort, 1991). In the Mediterranean, species in the Aphodiinae subfamily are mainly 94 endocoprids that feed and breed within the dung pat (although many species are known to be 95 kleptocoprids, saprophages and root feeders; Christensen \& Dobson, 1976; González-Megías \& 96 Sánchez-Piñero, 2003; Dellacasa \& Dellacasa, 2006). Whereas the Scarabaeinae subfamily 97 includes paracoprid and telecoprid species that feed and breed directly below or away from the 98 dung pat respectively (Hanski et al., 1991). The large abundances, relatively easy-to-identify 99 species, relative stable systematics and wide distribution of dung beetles, makes them ideal to 100 study spatial and temporal changes in community structure (Spector, 2006). Moreover, the 101 diversity of this group is known to respond to large-scale environmental gradients (Hortal-Muñoz, 102 Martin-Piera \& Lobo, 2000; Nunes et al., 2016), in particular to variations in water availability 103 (Haloti et al., 2006; Labidi et al., 2012; Tshikae et al., 2013a; Abdel-Dayem et al., 2016). In dry 104 areas dung beetles are thought to be constrained by both their physiological water economy 105 (Sowig, 1996; Chown, Sørensen \& Terblanche, 2011) and the decrease in the availability and 106 quality of trophic resources (Lumaret, 1995; Nichols et al., 2009). Further, Palearctic Scarabaeidae 107 are well diversified in mesic and arid Mediterranean areas (Lumaret, 1991; Sánchez-Piñero \& 108 Ávila, 2004) and surrounding desert regions (Baraud, 1985), making them a suitable model taxa 109 to investigate biodiversity responses to aridity gradients.

110 Here we study the temporal and spatial variations of dung beetle communities along a water 111 availability gradient in Eastern Morocco, spanning $400 \mathrm{~km}$ from coastal Mediterranean to desert

112 Saharan conditions. We aim to answer three specific questions: (Q1) Are dung beetle communities

113 of desert areas reduced subsets of communities living in less arid areas? (Q2) Are community

114 variations along the aridity gradient stable within and between years? (Q3) Do climatic factors, 
115 soil features and resource availability contribute to shape the diversity and composition of

116 communities along the aridity gradient? According to the water-energy hypothesis (Hawkins et

117 al., 2003), we expect a decrease in dung beetle diversity with increasing aridity. Progressively

118 dryer conditions will filter out the most sensitive species while selecting for highly adapted species

119 able to cope with a harsher climate and limited resource availability, thus promoting high spatial

120 species turnover and locally distinct species assemblages (Arakaki et al., 2011; Sánchez-Piñero et

121 al., 2011). In addition, we expect temporal shifts in the relationship between dung beetle diversity

122 and aridity, due to the strong variations in precipitation patterns. While in Mediterranean areas the

123 higher water availability during the wet season will cause a stronger diversity-aridity relationship

124 than in the dry season, desert environments will show lower seasonal species turnover but higher

125 inter-annual shifts in assemblage composition because the temporally stochastic nature of their

126 precipitations limits the adaptation to cope with seasonal environmental shifts (Tonkin et al., 127 2017).

128 Question Q1 was investigated by analysing species richness, abundance, evenness and 129 community composition along the aridity gradient. To answer question Q2 we analysed variations

130 in community composition at seasonal (between wet and dry seasons) and annual (between years)

131 temporal scales. Finally, we assessed question Q3 by analysing the effects of climate, soil, 132 vegetation and dung availability on dung beetle assemblages.

133

\section{MATERIALS \& METHODS}

\section{Study area}

136 We surveyed a linear transect spanning approximately $400 \mathrm{~km}$ in east Morocco, parallel to the

137 Algerian border (Figure 1). The transect was placed along a strong aridity gradient, from a semiarid 
138 region at the Mediterranean coast (near Saïdia, 35 $5^{\prime} 59^{\prime \prime} \mathrm{N}, 2^{\circ} 17^{\prime} 15^{\prime \prime} \mathrm{W}$ ) towards the hyperarid

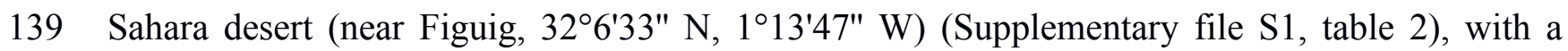

140 threefold annual rainfall gradient (from ca. $350 \mathrm{~mm}$ at the coastal semiarid area to $100 \mathrm{~mm}$ at the

141 nearly hyperarid Saharan end of the gradient) and a Mediterranean precipitation regime

142 characterized by summer drought and rainy season in November-March (Belda et al., 2014). The

143 difference in rainfall between the wet and dry seasons (as exemplified by the precipitation in April,

144 the wettest month, and September, the driest month) ranged from 45 to $19 \mathrm{~mm}$ at the semiarid end,

145 and showed no difference at the desert end (i.e. $13 \mathrm{~mm}$ in both months). However, during the dry

146 season, the greatest rainfall $(22 \mathrm{~mm})$ was not registered in the coast, but in the middle of the 147 gradient.

148 Livestock breeding is the main economic activity along the whole gradient. Sheep occur

149 along the entire transect, while cattle appears mainly in the semiarid end of the gradient toward

150 the Mediterranean coast. Donkeys also occur along the whole transect and dromedary herds appear

151 in the Saharan areas, but both are scarce. The transect is dominated by a single soil type (Petric

152 Calcisols) except the coastal area near Saïdia. This area shows coastal Gleyic Solonchak soil that

153 differ from the dominant Petric Calcisol because of a thicker silt layer ( $\geq 50 \mathrm{~cm}$ depth) and higher

154 salt concentration (Jones et al., 2013). The northern part of the transect mainly corresponds to

155 agricultural land, with forest areas restricted to mountain ranges, while the middle and the southern

156 parts are dominated by grazing rangelands with shrub vegetation $(20-30 \%$ cover, $25 \pm 13 \mathrm{~cm}$

157 height; mean $\pm \mathrm{SD})$.

158

159 Sampling design

160 Dung beetles were sampled during four campaigns held in two consecutive years: two in the wet 
161 season (April 2013 and 2014) and two in the dry season (September 2013 and 2014). These months

162 were chosen to include the two peaks of dung beetle richness and abundance in the Mediterranean

163 region (as recommended by Hortal \& Lobo, 2005). In each campaign we surveyed 10 sampling

164 sites along the Moroccan road N17 from the Sahara towards the Mediterranean, separated by an

165 interval of around $40 \mathrm{~km}$ (Figure 1). Sampling and beetle collection were carried out under research

166 permits Reference Numbers 01/2013 HCEFLCD/DLCDPN/DPRN/CFF and 01/2014

167 HCEFLCD/DLCDPN/DPRN/CFF issued by the Haut Commisariat aux Eaux et Forêts et à Lutte

168 Contre la Désertification (Morocco). All sampling sites were placed at least $100 \mathrm{~m}$ away from the

169 road margin. Annual precipitation was similar in both years at the three places with available

170 meteorological stations (Saïdia and Oujda in the north and Figuig in the south;

171 www.worldweatheronline.com), although it was about 20\% higher in 2012-2013 than in 2013-

1722014 in all three stations.

173 Each sampling site was replicated twice. Replicates were placed $1 \mathrm{~km}$ apart, and consisted

174 of five baited pitfall traps (thus, 100 traps per sampling campaign) separated $20 \mathrm{~m}$ one from another

175 following a straight line (thus, $80 \mathrm{~m}$ from trap 1 to trap 5). Each pitfall trap consisted of a 11 plastic

176 cup (11.5 cm diameter, $14 \mathrm{~cm}$ depth) covered by a $2 \mathrm{~cm}$ x $2 \mathrm{~cm}$ mesh on top of which $300 \mathrm{~g}$ fresh

177 cow dung was laid as bait (see Lobo, 1988). To avoid any spurious effects due to differences in

178 dung composition, fresh organic-farming cow dung was harvested from a single farm (Colmenar

179 Viejo, central Spain) and well-mixed to obtain a homogeneous dung mass, adding water and

180 mixing right before placing the traps to ensure adequate dung moisture levels. All traps were filled

181 with $300 \mathrm{ml}$ of a soapy preservative water solution with chloral hydrate $(10 \mathrm{~g} / \mathrm{l})$ to prevent quick

182 insect degradation due to high temperatures and fungi proliferation. Traps were active for a

183 standard period of $72 \mathrm{~h}$ (Labidi et al., 2012; Amraoui et al., 2016). All captures were immediately 
184 transferred to $96 \%$ ethanol in the field and transported to the lab where individuals were sorted

185 and identified to species level.

186 During the sampling campaigns we gathered data on resource availability, vegetation and

187 soil characteristics (Supplementary file S1, table 1$)$. GIS data on annual aridity (AI = mean annual

188 precipitation / mean annual evapotranspiration) and solar radiation were obtained from Trabucco

189 \& Zomer (2009), and mean monthly temperature, annual and monthly precipitation and altitude

190 from Hijmans et al. (2005). Resource availability was estimated using the amount of five types of

191 dung (sheep/goat, cow, horse/donkey, dromedary and carnivore droppings) present in the locality

192 as a general proxy for the actual amount of fresh dung that is available for dung beetles. To do

193 this, in each replicate in the four campaigns we conducted two perpendicular $250 \mathrm{~m}$ long and $2 \mathrm{~m}$

194 wide linear transects, each surveyed by one researcher following a standardized sampling protocol,

195 covering a total of $1000 \mathrm{~m}^{2}$ per replicate (similar to Lobo, Hortal \& Cabrero-Sañudo, 2006). In

196 each transect the total mass of the five types of dung mentioned above was estimated based on

197 dung volume, according to previous measurements of dung pats of different volume in the field

198 (González-Megías \& Sánchez-Piñero, 2004). Dung availability included “cow dung” and "sheep

199 + other dung" (all expressed in $\mathrm{g} / 100 \mathrm{~m}^{2}$ ). Vegetation height $(\mathrm{cm})$ and vegetation percentage cover

200 were estimated using the point-quarter method every $5 \mathrm{~m}$ along a $250 \mathrm{~m} \times 2 \mathrm{~m}$ transect at each

201 replicate and campaign to account for seasonal and yearly variations. Finally, we extracted three

202 arbitrarily located soil cores (4 cm diameter and $30 \mathrm{~cm}$ depth) from each replicate. Soil samples

203 were split into three depths $(0-10 \mathrm{~cm}, 10-20 \mathrm{~cm}$ and $20-30 \mathrm{~cm})$ and kept in separate air-tight plastic

204 bags for further laboratory analyses. From these samples, seven soil variables were measured

205 (Supplementary file S1, table 1) accounting for structure (hardness, bulk density), water content

206 (water field capacity) and particle size (percentage of gravel, sand, silt, and clay) (see Tovar, 2015). 


\section{Statistical analyses}

209 We assessed inventory completeness for each sampling site at each campaign using Sample

210 Coverage (Chao \& Jost, 2012) as implemented in iNEXT R package (Hsieh, Ma \& Chao, 2016).

211 Average sample coverage was $99.18 \%$, with a minimum of $91.50 \%$ for the site located at the

212 semiarid end of the gradient in the wet season of 2014. For this reason, species richness $(S)$ was

213 measured as the total number of species recorded in each sampling site at each sampling campaign.

214 Evenness $\left(J^{\prime}\right)$ was measured using Pielou's index, i.e. Shannon $H^{\prime} / \ln (S)$ (Magurran, 2004).

\section{Variations of species richness, abundance, and evenness along the aridity gradient}

217 We analysed the relationship between aridity and species richness, abundance (mean number of

218 individuals/trap) and evenness (question Q1) through a multivariate general linear regression

219 (GLM) with restricted sigma parameterization. We considered aridity and its interactions with both

220 season and year as factors, to assess their eventual influence on the relationship between

221 community descriptors and aridity. The 'aridity * season * year' interaction was also included to

222 assess whether these relationships show different seasonal patterns in the two study years.

223 Significance levels were Bonferroni-corrected, since the same analysis was carried out for three

224 different response variables (richness, abundance and evenness).

225

\section{Variations in community composition}

227 To assess variations in community composition (questions Q1 and Q2) we used non-metric 228 multidimensional scaling (NMDS; Quinn \& Keough, 2002), based on the Bray-Curtis similarity 229 index. Abundance was Hellinger standardized prior to the similarity analyses, to balance relative 
230 abundances of species and minimize the double-zero problem typical of community samples

231 (Legendre \& Gallagher, 2001). Pairwise differences in Bray-Curtis similarity at each site between

232 years, seasons and their interaction (independent of aridity) were analyzed by means of a

233 PERMANOVA (9999 iterations) using PAST 3.15 statistical package (Hammer, Harper \& Ryan, 234 2001).

236 In addition, we used a beta diversity partitioning framework based on both presence-absence data

237 using Sørensen's dissimilarity index and abundance data using Bray-Curtis dissimilarity index.

238 First, Sørensen dissimilarity was partitioned into its "true species turnover" (i.e. species

239 replacement) and "nestedness" (i.e. species loss) components (Baselga \& Orme, 2012). This

240 partitioning of dissimilarity only accounts for presence-absence variations in the data (Baselga et

241 al., 2013), so to consider also species abundances we followed a similar procedure. We calculated

242 abundance-based Bray-Curtis dissimilarity index (herein B-C dissimilarities for short),

243 partitioning it into "balanced" (i.e. substitution of individuals of one species in one site by the same

244 number of individuals of different species in another site) and "gradient" (i.e. loss of individuals

245 from one site to another) components (Baselga, 2013). Multiple site dissimilarity was used to

246 calculate overall beta diversity partitioning in the turnover/nestedness and balanced/gradient

247 components of Sørensen and B-C dissimilarities, respectively, for each season in each year (i.e.,

248 for each one of the four campaigns). To analyze whether turnover/nestedness and

249 balanced/gradient components of Sørensen and B-C dissimilarities varied along the aridity

250 gradient, we carried out non-parametric Spearman-rank correlations between pairwise

251 dissimilarities and the differences in aridity between each pair of sites. We used Sperman-rank

252 correlations because residuals from GLM models did not fit a normal distribution and were 
253 heteroscedastic. All Sørensen and B-C dissimilarities calculations were done using the R package

254 Betapart 1.5.0 (Baselga et al., 2013). In addition, we identified the most representative species of

255 three sections of the transect representing the semiarid end, the intermediate zone and the arid end

256 for each year and season using the Indicator Value Index (IndVal), calculated with the R package

257 indicspecies (DeCaceres \& Legendre, 2009). Due to small sample size, a Wilcoxon signed rank

258 test was carried out to test whether the Scarabaeinae/Aphodiinae abundance ratios were lower in

259 the dry than in the wet season, using the R package stats.

260 We also used Sørensen's and B-C dissimilarities to analyse variations in community

261 composition between seasons (wet vs dry) and between years (2013 vs 2014) for each one of the

262 ten points along the transect. Then, to analyse whether these site similarities between seasons and

263 between years were related to (continuous) variations in aridity we carried out a multivariate GLM

264 with restricted sigma parameterization considering aridity and its interactions with both season 265 and year.

266

267 Relationship of environmental variables with diversity and composition of communities

268 We evaluated the relationships of richness, abundance and evenness with climate, soil, vegetation 269 and dung availability (question Q3) through partial least squares generalized lineal regressions

270 (PLS-GLR; Bastien, Vinzi \& Tenenhaus, 2005). This method allows analysing data characterized

271 by a large number of multicollinear predictor variables by extracting a set of orthogonal

272 components (or latent vectors) considering not only the structure of predictor variables (as

273 provided by a PCA) but also their relationship with the response variable. Once the components

274 were computed, a GLM with Gaussian function and identity link of the response variable on the

275 PLS components was carried out in order to test for the significance of the components and the 
276 whole model. Abundance data were $\log 10$-transformed to meet assumptions of homoscedasticity

277 and normality of model residuals. Because communities differed mainly between seasons (see

278 Results below), four PLS-GLR analyses were conducted (2 descriptor variables $\times 2$ seasons) and

279 the critical significance level of the models was set by Bonferroni correction $(\mathrm{p}<0.0125)$. Cross-

280 validation and corrected Akaike Information Criterion (AICc), due to low sample size were used

281 to select among models including different number of components. When a model component

282 coefficient was not significant ( $\mathrm{p}>0.0125$ ), the next optimal model indicated by cross-validation

283 and AICc was chosen. To identify the importance of each predictor in the model, the standardized

284 coefficients of the final PLS-GLR model were obtained by bootstrapping (1000 iterations).

285 We assessed the best combination of environmental variables explaining variations in

286 species composition (question Q3) through multivariate RDA-based variation partitioning

287 (Borcard, Gillet \& Legendre, 2011) (Supplementary file S3, Figure 1). Further, we used distance-

288 based RDA (dbRDA) to assess the best predictors of Sørensen's and Bray-Curtis dissimilarities

289 between all sites in each campaign. In both cases (RDA and dbRDA) we previously forward

290 selected environmental and spatial predictors applying the two-step procedure proposed by

291 Blanchet, Legendre \& Borcard (2008) to select significant predictor variables. We calculated the

292 amount of variation of the different biodiversity metrics explained by the different groups of

293 predictors (climate, space, soil and dung, as found in Supplementary file S1, table 1) and evaluated

294 the significance of the pure fractions (for each group of variables accounting for the variance

295 explained by all other factors) using partial RDA for species composition and partial dbRDA for 296 Sørensen and B-C dissimilarities.

We performed a spatial autocorrelation analysis to account for any spatially-structured

298 unexplained variability. We did this by including the vectors obtained from a Moran's Eigenvector 
299 Map (Borcard et al., 2004; Borcard et al., 2011) into the analyses. These vectors were calculated

300 using R packages spdep (Bivand \& Piras, 2015) and spacemakeR (Dray, 2013). PLS-GLR analyses

301 were conducted using the R package plsRglm (Bertrand, Meyer \& Maumy-Bertrand, 2014), and

302 the multivariate variation partitioning analyses with the function varpart of $\mathrm{R}$ package vegan

303 (Oksanen et al., 2016).

304

305 RESULTS

306 We captured 70,326 individuals of 61 dung beetle species in the four sampling campaigns $(9,627$

307 individuals of 29 Scarabaeinae species and 60,699 individuals of 32 Aphodiinae species; see

308 Supplementary file S2). Overall, dung beetle abundance and richness were slightly higher in 2014

309 compared to 2013 for both seasons (Figure 2).

310

311 Variations in species richness, abundance and evenness

312 There was a significant pattern of decreasing species richness along the gradient, but neither

313 abundance nor evenness showed a significant relationship with aridity (Figure 2, Table 1). The

314 relationship between species richness and aridity strongly varied seasonally, with a higher slope

315 of the Season*Aridity interaction in the wet than in the dry season. The significant Year*Aridity

316 interaction indicates that the relationship between species richness and aridity varied between

317 years, 2014 showing a steeper slope than 2013 due to the higher number of species in the semiarid

318 end of the transect, but not in the desert areas (Table 1, Figure 2). In fact, species richness showed

319 a clear change only during the wet season, from low values (5-10 species) in the desert to the

320 highest richness (15-20 species) in the semiarid zone (Figure 2). During the dry season, species

321 richness hardly increased from the desert to semiarid areas in 2013, although a slight increase 
322 appeared near the semiarid end of the gradient, particularly in 2014.

323 Total abundance did not show a significant relationship with aridity and was very similar

324 along the gradient in both sampling seasons (Table 1, Figure 2). The wet season showed relatively

325 small variations of abundances throughout the gradient, with a decrease at both ends, while there

326 was a striking increase in abundance in the semiarid end of the gradient in the dry season (Figure

327 2). Although evenness was not directly related to aridity, there was a significant Season*Aridity

328 interaction (Table 1), indicating that evenness patterns change throughout the year along the

329 gradient, especially because of the contrasting evenness values between the wet and the dry

330 seasons at the semiarid end of the transect (Figure 2).

331

332 Variations in community composition

333 Although there were no significant relationships of total abundance with aridity, there were large

334 seasonal differences in the relative abundance at the subfamily level. Communities in the wet 335 season were dominated by Scarabaeinae, which accounted for $60-90 \%$ of total abundance in most 336 sites. This contrasts with the dry season, when the communities were almost dominated by 337 Aphodiinae, which accounted for more than $97 \%$ of abundance in most sites. Thus, the ratio of 338 Scarabaeinae/Aphodiinae abundances significantly differed between seasons (2013: $\chi^{2}=$ 339 10632.53, $\left.\mathrm{p}<0.001 ; 2014: \chi^{2}=22483.74, \mathrm{p}<0.001\right)$. However, these differences did not hold for 340 richness, which showed approximately a 1:1 ratio in the number of species in both seasons.

341 Community composition along the aridity gradient showed a strong seasonal structure. The

342 communities during the wet and dry seasons were clearly different, except in the most arid extreme

343 of the gradient (specially sites 2 and 3), as shown by NMDS ordination (Figure 3). While NMDS

344 shows a clear spatial structure in community composition along the gradient in the wet season, in 
345 the dry season only the semiarid end of the transect (sites 8-10) shows a marked difference with

346 all the other sites (Figure 3). PERMANOVA results corroborate that community composition

347 significantly differed seasonally ( $\mathrm{pseudoF}=8.255, \mathrm{p}<0.0001$, d.f. $=1,36)$ while showing similar

348 patterns in both sampling years $(\mathrm{pseudoF}=1.341, \mathrm{p}=0.1968$, d.f. $=1,36)$, with no significant

349 interaction between both factors $(p s e u d o F=0.604, p=0.805$, d.f. $=1,36)$. Changes in community

350 composition between years were indeed small, with total Sørensen values of 0.2 and 0.3 for the

351 wet and dry season respectively (Figure 4a), and total B-C of 0.3 in the wet season and 0.2 in the

352 dry season (Figure 4b). Indeed, the indicator species of communities (IndVal analyses) sampled

353 were the same in 2013 and 2014 (see Appendix S3, Table 1). In contrast, three Aphodiinae species

354 were indicators of communities sampled during the dry season (IndVal $>0.95$ ), while seven

355 Scarabaeinae and seven Aphodiinae species were indicators of wet season communities (see

356 Supplementary file S3, table 4).

357

358 Variations in community dissimilarities in space and time

359 Dissimilarity between wet and dry season communities (both Sørensen and B-C) significantly

360 decreased with aridity (Figure 4), and there was no interaction with year (Table 2). In contrast,

361 Sørensen dissimilarity between 2013 and 2014 communities was not affected by aridity (Figure

362 4), although B-C dissimilarity significantly increased with aridity with an interaction with season

363 due to the stronger pattern occurring in the dry season (Table 2, Figure 4). Hence, total B-C

364 dissimilarity was low between seasons in the most arid sites, but very high towards the semiarid

365 end of the gradient (Figure $4 b)$.

366 Multisite Beta diversity-partitioning showed that Sørensen dissimilarity among sites was

367 mainly due to species turnover along the gradient in both seasons, although nestedness increases 
368 in importance in the dry season (Figure 5a). In contrast, according to B-C dissimilarity analyses

369 balanced changes in abundance were prevalent in both seasons, with some gradient in the wet

370 season (Figure 5b). This pattern was similar in both years. Interestingly, both pairwise Sørensen

371 and B-C dissimilarities showed similar relationships with pairwise differences in aridity. The

372 turnover and balanced components increased in relation to differences in aridity between sites,

373 while nestedness and gradient components did not change significantly with differences in aridity

374 (Table 3).

375

376

Relationships of environmental variables with the diversity and composition of communities

The PLS-GLR analysis shows that the relationship between environmental variables and

species richness and abundance along the gradient largely differed between seasons. Results for

evenness are not shown as data did not meet the premises of neither normality nor homocedasticity

for the wet season and were not significant for the dry season. PLS components were only 381 significantly related to species richness variations in the wet season and to abundance variations in the dry season (Supplementary file S3, table 5). PLS standardized coefficients indicate that variations of species richness in the wet season were positively related to precipitation (both monthly and annual rainfall) and negatively related to radiation (Figure 6a). Differences of abundance in the dry season appeared positively related to cow dung availability (Figure 6b). and B-C dissimilarities and raw community composition with climate, space, soil and dung availability (Supplementary file S3, figure 1). As expected, space and climate explained a large proportion of the variance in all cases, although in a few cases this latter factor only rendered 
391 small proportion of the variance in B-C dissimilarities and community composition, mainly in both

392 seasons of 2013. Variation of Sørensen dissimilarity in all campaigns was irregularly explained

393 (and rarely significantly, see Supplementary file S3, figure 1) solely by climate and space (from

$39471 \%$ to only $23 \%$ ), with the only exception of the dry season of 2013 , where dung availability also

395 explained a marginal $4 \%$.

396

397 DISCUSSION

398 Although our results support the general expectation that water availability is a major factor

399 structuring the diversity of communities in semiarid environments, they provide novel insights on

400 how such relationship affects community structure through time. Even though dung beetle species

401 richness shows a clear decrease with increasing aridity, contrary to our expectations abundance

402 and evenness did not change along the gradient. And importantly, aridity fosters a gradual

403 replacement of species, so the most arid areas are inhabited by distinct assemblages of dung beetle

404 species adapted to the dry and resource-poor desert conditions, rather than poor subsets of the less

405 arid areas (our question Q1). But perhaps the most striking of our results is that diversity-aridity

406 relationships show marked seasonal differences (our question Q2). And further, these changes may

407 be consistent between years, rather than stochastic. This, together with the somehow unexpected

408 lack of predictive power of resource (dung) availability (our question Q3) points to a strong

409 environmental filtering as the major process behind not only of the distribution of dung beetles

410 along the studied gradient, but also of their phenology.

411 Low water availability and/or precipitation is known to limit the diversity of many

412 organisms (e.g., Sommer et al., 2010; Maestre et al., 2015), including dung beetles (e.g. Hortal,

413 Lobo \& Martin-Piera, 2001; Tshikae, Davis \& Scholtz, 2013b, c). Such negative relationship is 
414 however inexistent or even reversed in other organisms and/or systems (Polis, 1991; Polis et al.,

415 1997; Delsinne et al., 2010; Andersen et al. 2015). Water availability may determine species

416 richness through two main mechanisms: physiological constraints (Chown et al., 2011) - thus

417 following the water-energy hypothesis (Hawkins et al., 2003a); and resource availability (Nichols

418 et al., 2009; Tshikae et al., 2013c) -following the species-energy hypothesis (Wright, 1983).

419 While precipitation was directly related to species richness in our analysis, supporting the 420 prediction of the water-energy hypothesis, dung availability did not correlate with species richness

421 in our study. This is consistent with the claims that many other factors not directly related to

422 resource availability may determine large-scale diversity gradients (e.g. Currie et al., 2004;

423 Hurlbert \& Jetz, 2010). In the case of our gradient, the higher dung beetle richness at the semiarid

424 end near the coast may be sustained by the increase in diversity of dung types provided by the 425 appearance of cow herds (Lobo et al., 2006; Tshikae et al., 2013b). Further, some Aphodiinae 426 species are generalist saprophages (Christensen et al., 1976; Dellacasa et al., 2006; Holter, Scholtz 427 \& Stenseng, 2009), so the higher availability of detritus resources (not quantified in this study) such as leaf litter in this area of higher plant production may be also promoting a higher richness. with increasing aridity towards the Sahara. This result is also in contradiction with the speciesenergy hypothesis, and the general argument that greater productivity can maintain more 432 individuals and therefore viable populations of a larger number of species (Hutchinson, 1959; 433 Brown, 1981; Wright, 1983). Instead, we found an unexpected decline in abundance at the 434 semiarid end of the gradient in the wet season. This area was, by far, the one with higher 435 availability of cattle dung (Supplementary file S1, table 2), the richest resource present in the whole 436 gradient, so it is unlikely that such low numbers are due to limited resource availability. Rather, 
437 the lower abundance of dung beetles in the coastal site may be partly explained by both land use

438 intensification caused by cropland and urban spread (Davis, Scholtz \& Swemmer, 2012; Nichols

439 et al., 2013) and/or the higher salinity of the deep and superficial layers of the soil -that may deter

440 burying dung beetle species to nest. Further, the large increase of beetle abundance at this area

441 during the dry season was due to a single species, the aphodiid Anomius baeticus. This

442 saprophagous beetle feeds on plant detritus (Sánchez-Piñero et al., 2004; Verdú \& Galante, 2004),

443 which enables it to have massive population outbreaks in the dry season.

444 Strikingly, changes in community composition along the gradient follow an ordered

445 replacement with aridity rather than a mere loss of species, although the rate of such replacement

446 is progressively lower towards the Sahara. Most variation in composition was due to a balanced

447 turnover in all surveys, with both Sørensen and B-C dissimilarities increasing towards the

448 Mediterranean coast. Despite the decrease in species richness with increasing aridity, nestedness

449 and gradient compositional changes were much smaller, remaining constant throughout the whole

450 gradient. Such pre-eminence of species replacement indicates that the strong filtering imposed by

451 aridity is not limited to the progressive inability of the species adapted to Mediterranean conditions

452 to inhabit desert areas. Rather, there is a distinct pool of dung beetle species adapted to arid Saharan

453 conditions (e.g. Onthophagus transcaspicus, Scarabaeus aegyptiacus, Mendidius palmenticola or

454 Calasmosternus lucidus; Baraud, 1985), that progressively substitutes the semiarid elements of the

455 communities. These species are seemingly adapted to the low -and stochastic- availability of

456 resources, and form distinct communities compared to neighbouring areas with more mesic

457 environments (Sánchez-Piñero et al., 2011). Extreme arid conditions determine the occurrence of

458 a highly adapted biota in desert ecosystems (Arakaki et al., 2011), usually including a high

459 proportion of endemics (Le Houérou, 2001). Whether this pattern of pre-eminence of species 
460 replacement with increasing aridity is common in desert communities needs further investigation

461 since no other studies partitioned beta diversity along aridity gradients before.

462 Importantly, although the general pattern of decrease in richness and balanced turnover along the

463 gradient holds on for all surveys, our results also show important temporal variations. Indeed, the

464 significance of the interactions of season and year with aridity evidence that the effect of water

465 availability on species richness changes in time. Dung beetle faunas showed strong seasonal

466 changes, with a steeper decline of richness with aridity in the wet season. In arid and semiarid

467 environments this season is not only characterized by milder climate, but also by the higher

468 abundance and quality of trophic resources (Hanski, 1987). Further, the richness-precipitation

469 relationship was weaker in 2013 than in 2014 -with no significant changes in species richness

470 across the gradient in the dry season of the former year. These differences may be related to

471 temporal changes in precipitation, as this factor was an important predictor of richness in spring

472 but not in the dry season. The marked precipitation gradient along the transect in spring contrasts

473 with the scarce difference in the amount of rain along the gradient at the end of the summer-early

474 fall (from 46 to 13 and 22 to $13 \mathrm{~mm}$ of monthly precipitation, respectively). Spring precipitations

475 allow a higher plant productivity that in turn results in more hydrated dung of better quality for

476 nesting (Lumaret, 1995), and ultimately higher reproductive success and the emergence of larger

477 populations in the next generation. Indeed, annual precipitation was higher in 2013 than in 2012,

478 allowing a higher abundance of dung beetles emerging the year after because of the higher

479 reproductive success in 2013. Long-term data would be strongly needed to analyse these temporal

480 changes in species richness and precipitation.

481 The spatial structure of dung beetle assemblages along the transect also varied in time.

482 During the favourable conditions of the wet season species composition followed a structured 
483 sequence of replacement from the semiarid sites to the desert. This structure was disassembled in

484 the harsher dry season, when assemblages were largely homogeneous, particularly in the arid and

485 nearly hyperarid areas, and only the three sites in the semiarid end of the gradient showed

486 compositional differences. Importantly, the temporal changes in composition at each site also

487 varied in relation to aridity. Seasonal variations in species dissimilarity were lower as aridity

488 increased, regardless of the relative effects of abundance. Similar findings have been reported for

489 ant assemblages along an elevational gradient (Bishop et al., 2014), and corroborate the prediction

490 that seasonal variations in assemblage composition are lower in more unpredictable habitats

491 (Hawkins et al., 2003a). Hence, our results may indicate that desert communities inhabiting highly

492 unpredictable systems show a higher seasonal similarity than more mesic sites. This is likely due

493 to the ability of some species to cope with the harsh desert conditions regardless of the season

494 (Pierre, 1958; Noy-Meir, 1974; Heatwole, 1996; Ghabbour \& Mikhail, 1997).

495 In contrast, the most unpredictable arid habitats showed higher inter-annual compositional

496 variations. However, these inter-annual differences were only significant when accounting for

497 species abundances through the use of Bray-Curtis dissimilarities. This indicates that species

498 composition at each season remains relatively constant from one year to another, and community

499 structure only changes according to the variations in abundance. This is particularly true in the dry

500 season, as revealed by the importance of the season*aridity interaction when analysing inter-

501 annual variations in B-C dissimilarity. Differences in assemblage composition between two

502 consecutive years in arid areas of SE Spain were mainly due to the differences in abundance of a

503 single species, Anomius baeticus, which abundance differed one order of magnitude between the

504 two years (Sánchez-Piñero et al., 2011). Large differences between consecutive years in the

505 abundance of particular species are characteristic of Mediterranean arid systems (Noy-Meir, 1974; 
506 Sánchez-Piñero et al., 2011). Our results are consistent with the predictions that inter-annual

507 variations in assemblage composition will be higher in more unpredictable habitats (Tonkin et al., 508 2017), although studies considering a greater number of years will be necessary, especially in the 509 more unpredictable desert sites (Polis, 1991).

510 Interestingly, changes in aridity through space and time also promote a spatio-temporal

511 shift in the dominance of the two dung beetle subfamilies, Scarabaeinae and Aphodiinae.

512 Aphodiinae are more abundant in the desert communities during the wet season (see also Abdel-

513 Dayem et al., 2016), a change that may be related to a spatial shift in dung use strategies forced by

514 environmental conditions. While all Mediterranean Scarabaeinae species are either paracoprids or

515 telecoprids, the Aphodiinae include endocoprid, saprophagous and kleptocoprid species (Sánchez-

516 Piñero, 1994; González-Megías et al., 2003). Hence, the observed changes in relative abundance

517 of Aphodiinae in the desert communities in the wet season, also reported in previous studies

518 (Labidi et al., 2012; Abdel-Dayem et al., 2016), result in a functional shift from para- and

519 telecoprid beetles to endocoprids and more generalist saprophagous species. Such shift also occurs

520 in time, for Aphodiinae dominate in abundance during the dry season throughout the whole

521 gradient (totalling $>95 \%$ of individuals in all local communities), a pattern also found in other

522 Mediterranean dung beetle assemblages (e.g. Sánchez-Piñero et al., 2004; Sullivan et al., 2016).

523 In fact, our results suggest that the ability of many Aphodiinae species to use different resources

524 for feeding and nesting may allow them to maintain populations in more limiting dry conditions

525 (both in more arid areas as well as in drier seasons), and their relative abundance will diminish

526 when and where milder conditions allow Scarabaeinae to thrive and hold large populations and

527 species-rich communities. Whether this is merely an effect of differences in environmental

528 filtering between the two groups or by the eventual displacement of Scarabaeinae species by the 
529 superior competitive ability in dry conditions of the copro-saprophagous Aphodiinae remains an

530 open question.

531

532 CONCLUSIONS

533 To summarize, climate-driven environmental filtering is the main process shaping the structure of

534 dung beetle communities along the aridity gradient studied here. However, such filtering may be

535 partly related with the availability of high-quality resources for feeding and nesting. In fact, the

536 diversity-aridity relationship changes through time, determined by the highly variable seasonal

537 and inter-annual patterns of precipitation, that in turn affect the quality and quantity of mammal

538 dung. This results in a ordered replacement of functionally-different species in space and time, as

539 generalist and saprophagous dung beetles become dominant in desert conditions and dryer seasons

540 and years. That is, desert communities are not impoverished subsets of species from species-rich

541 communities from milder climatic conditions, but unique combinations of species adapted to such

542 conditions. Whether this pattern of pre-eminence of species replacement with increasing aridity is

543 common in desert communities needs further investigation since no other studies partitioned beta

544 diversity along aridity gradients before. The limited temporal extent of our study does not allow

545 assessing the effects of large inter-annual changes in precipitation either, but it can however be

546 expected that semiarid dung beetle faunas respond to the climate change-driven progressive

547 aridification of East Mediterranean with large functional changes in community structure (see

548 Tonkin et al., 2017). The loss of spatial structure of the dung beetle communities in the dry season

549 for most of the gradient points to a reduction of richness and a higher homogeneity of assemblages

550 if drought becomes a pervasive factor. Indeed, the expected lower seasonal changes in precipitation

551 in progressively more arid conditions is likely to result in a generalized loss of diversity with 
552 climate change. But beyond these general patterns of change, the exact nature behind dung beetle

553 responses to aridity remains elusive. Data on functional traits, physiological responses to aridity

554 and long-term community variations are needed to understand the complex mechanisms behind it.

555

556 ACKNOWLEDGEMENTS

557 We are grateful to Prof. Guy Chavanon for obtaining the sampling permits from the Moroccan 558 authorities, and the Haut Commissariat aux Eaux et Forêts et à la Lutte Contre la Désertification

559 (Direction de la Lutte Contre la Désertification et de la Protection de la Nature) for permission to 560 conduct this research. Pedro Sandoval greatly helped in sorting samples and species identification.

561 Maria de la Luz Tovar and Francisco Martín Peinado (Department of Edaphology, University of

562 Granada) carried out the analysis of soil characteristics. We thank Daniel Borcard for advice on 563 multivariate variation partitioning and Luis María Carrascal for his invaluable help to conduct

564 PLS-GLR analyses. We thank two anonymous reviewers for their careful reading of our

565 manuscript and their many insightful comments and suggestions. Several researchers, graduate

566 and postgraduate students helped during field campaigns. Thanks to B. Rambert, N. Schriber and

567 M. Julitta for logistic support in Zurich. Finally, special thanks to Elena Cáceres Díaz for 568 motivational support. 
570

571

572

573

574

575

576

577

578

579

580

581

582

583

584

585

586

587

588

589

590

591

592

593

594

595

596

597

598

599

600

601

\section{REFERENCES}

Abdel-Dayem, M.S., Kondratieff, B.C., Fadl, H.H. \& Al Dhafer, H.M. 2016. Dung beetle (Coleoptera: Scarabaeidae) abundance and diversity at nature preserve within hyper-arid ecosystem of Arabian peninsula. Annals of the Entomological Society of America 109:216223 DOI: 10.1093/aesa/sav154.

Agoglitta, R., Moreno, C.E., Zunino, M., Bonsignori, G. \& Dellacasa, M. 2012. Cumulative annual dung beetle diversity in Mediterranean seasonal environments. Ecological research 27:387-395 DOI: 10.1007/s11284-011-0910-8.

Amraoui, S., Bouragba, N., Brague, A. \& Lumaret, J.-P. 2016. Dung beetles (Coleoptera: Scarabaeoideae) between a natural forest and a reforested steppe (Djelfa, Algeria). Turkish Journal of Forestry 17:23-30 DOI: 10.18182/tjf.68167.

Andersen, A.N., Toro, I.D. \& Parr, C.L. 2015. Savanna ant species richness is maintained along a bioclimatic gradient of increasing latitude and decreasing rainfall in northern Australia. Journal of Biogeography 42:2313-2322 DOI: 10.1111/jbi.12599.

Arakaki, M., Christin, P.-A., Nyffeler, R., Lendel, A., Eggli, U., Ogburn, R.M., Spriggs, E., Moore, M.J. \& Edwards, E.J. 2011. Contemporaneous and recent radiations of the world's major succulent plant lineages. Proceedings of the National Academy of Sciences 108:83798384 DOI: 10.1073/pnas.1100628108.

Baraud, J. (1985) Coléoptères Scarabaeoidea: faune du nord de l'Afrique du Maroc au Sinaï. Lechevalier, Paris.

Baselga, A. 2013. Separating the two components of abundance-based dissimilarity: balanced changes in abundance vs. abundance gradients. Methods in Ecology and Evolution 4:552557 DOI: 10.1111/2041-210x.12029.

Baselga, A. \& Orme, C.D.L. 2012. betapart: an R package for the study of beta diversity. Methods in Ecology and Evolution 3:808-812 DOI: .

Baselga, A., Orme, D., Villeger, S., Bortoli, J.D. \& Leprieur, F. (2013) betapart: Partitioning beta diversity into turnover and nestedness components. $R$ package version 1.3 . $<$ http://CRAN.Rproject.org/package=betapart>.

Bastien, P., Vinzi, V.E. \& Tenenhaus, M. 2005. PLS generalised linear regression. Computational Statistics \& Data Analysis 48:17-46 DOI: 10.1016/j.csda.2004.02.005.

Belda, M., Holtanová, E., Halenka, T. \& Kalvová, J. 2014. Climate classification revisited: from Köppen to Trewartha. Climate research 59:1-13 DOI: 10.3354/cr01204. 
602 Bertrand, F., Meyer, N. \& Maumy-Bertrand, M. (2014) plsRglm: Partial least squares regression

603 for generalized linear models. $R$ package version 1.1.1. $<$ https://cran.r-

$604 \quad$ project.org/package $=$ pls $>$.

605 Bishop, T.R., Robertson, M.P., Rensburg, B.J. \& Parr, C.L. 2014. Elevation--diversity patterns

606 through space and time: ant communities of the Maloti-Drakensberg Mountains of southern

607 Africa. Journal of Biogeography 41:2256-2268 DOI: 10.1111/jbi.12368.

608 Bivand, R. \& Piras, G. 2015. Comparing implementations of estimation methods for spatial

609 econometrics. Journal of Statistical Software 63:1-36 DOI: 10.18637/jss.v063.i18.

610 Blanchet, F.G., Legendre, P. \& Borcard, D. 2008. Forward selection of explanatory variables.

611 Ecology 89:2623-2632 DOI: 10.1890/07-0986.1.

612 Borcard, D., Gillet, F. \& Legendre, P. (2011) Numerical ecology with R. Springer Verlag, Berlin, 613 Germany.

614 Borcard, D., Legendre, P., Avois-Jacquet, C. \& Tuomisto, H. 2004. Dissecting the spatial

615 structure of ecological data at multiple scales. Ecology 85:1826-1832 DOI: 10.1890/03-

$616 \quad 3111$.

617 Brown, J. 1981. Two Decades of Homage to Santa Rosalia: Toward a General Theory of

618 Diversity. American Zoologist 21:877-888 DOI: 10.1093/icb/21.4.877.

619 Chao, A. \& Jost, L. 2012. Coverage-based rarefaction and extrapolation: standardizing samples 620 by completeness rather than size. Ecology 93:2533-2547 DOI: 10.1890/11-1952.1.

621 Chown, S.L., Sørensen, J.G. \& Terblanche, J.S. 2011. Water loss in insects: An environmental change perspective. Journal of Insect Physiology 57:1070-1084 DOI:

624

625

626 10.1016/j.jinsphys.2011.05.004.

Christensen, C.M. \& Dobson, R. 1976. Biological and ecological studies on Aphodius distinctus (Mueller)(Coleoptera: Scarabaeidae). The American Midland Naturalist 95:242-249 DOI:

627 $10.2307 / 2424257$.

628

Currie, D.J., Mittelbach, G.G., Cornell, H.V., Field, R., Guégan, J., Hawkins, B.A., Kaufman,

629 D.M., Kerr, J.T., Oberdorff, T., O'Brien, E. \& Turner, J.R.G. 2004. Predictions and tests of climate-based hypotheses of broad-scale variation in taxonomic richness. Ecology Letters

631 7:1121-1134 DOI: 10.1111/j.1461-0248.2004.00671.x.

632

633

Davis, A., Scholtz, C. \& Swemmer, A. 2012. Effects of land usage on dung beetle assemblage structure: Kruger National Park versus adjacent farmland in South Africa. Journal of Insect Conservation 16:399-411 DOI: 10.1007/s10841-011-9426-3.

634

635

DeCaceres, M. \& Legendre, P. 2009. Associations between species and groups of sites: indices and statistical inference. Ecology 90:3566-3574 DOI: 10.1890/08-1823.1. 
636 Dellacasa, G. \& Dellacasa, M. (2006) Fauna d'Italia. Coleoptera, Aphodiidae, Aphodiinae.

637 Edizioni Calderini, Bologna, Italy.

638 Delsinne, T., Roisin, Y., Herbauts, J. \& Leponce, M. 2010. Ant diversity along a wide rainfall

639 gradient in the Paraguayan dry Chaco. Journal of arid environments 74:1149-1155 DOI:

$640 \quad 10.1016 /$ j.jaridenv.2010.03.014.

641

642

643

644

645

Dray, S. (2013) spacemakeR: Spatial modelling. $R$ package version 0.0-5/r113. $<$ http://RForge.R-project.org/projects/sedar/>.

Ghabbour, S.I. \& Mikhail, W.Z. 1997. Soil mesofauna in unstable environments and their population density-biomass relationship: Cases from the Egyptian deserts. Geobios 30:135-

646 144 DOI: 10.1016/S0016-6995(97)80080-0.

González-Megías, A. \& Sánchez-Piñero, F. 2003. Effects of Brood Parasitism on Host Reproductive Success: Evidence from Larval Interactions among Dung Beetles. Oecologia 134:195-202 DOI: $10.1007 / \mathrm{s} 00442-002-1100-8$.

González-Megías, A. \& Sánchez-Piñero, F. 2004. Resource limitation of nesting: Chance favors the prepared dung beetle. Environmental Entomology 33:188-196 DOI: 10.1603/0046-225X33.2.188.

Gouveia, S.F., Hortal, J., Cassemiro, F.A.S., Rangel, T.F. \& Diniz-Filho, J.A.F. 2013. Nonstationary effects of productivity, seasonality, and historical climate changes on global amphibian diversity. Ecography 36:104-113 DOI: 10.1111/j.1600-0587.2012.07553.x.

Haloti, S., Janati-Idrissi, A., Chergui, H. \& Lumaret, J.-P. 2006. Structure des communautés de Sacarabéides coprophages du Maroc nord-occidental (Coleoptera, Scarabaeoidea). Bulletin

Hammer Ø., Harper D.A.T., \& Ryan P.D. 2001. PAST: Paleontological Statistics Software Package for Education and Data Analysis. Palaeontologia Electronica 4:1-9.

660

Hanski, I. (1987) Nutritional ecology of dung-and carrion-feeding insects. Nutritional ecology of

661

662

663

664 insects, mites, spiders and related invertebrates (ed. by Slansky, F. \& Rodriguez, J.), pp.

665

666 837-884. John Wiley and Sons, New Jersey, USA.

Hanski, I. \& Cambefort, Y. (1991) Dung beetle ecology. Princeton University Press, Princeton, USA.

667

668

Hawkins, B.A., Field, R., Cornell, H.V., Currie, D.J., Guégan, J.-F., Kaufman, D.M., Kerr, J.T., Mittelbach, G.G., Oberdorff, T., O'Brien, E.M., Porter, E.E. \& Turner, J.R.G. 2003 a.

3117 DOI: $10.1890 / 03-8006$

669 Hawkins, B.A. \& Porter, E.E. 2003b. Water-energy balance and the geographic pattern of 
670

671

672

673

674

675

676

677

678

679

680

681

682

683

684

685

686

687

688

689

690

691

692

693

694

695

696

697

698

699

700

701

702

703

species richness of western Palearctic butterflies. Ecological Entomology 28:678-686 DOI: 10.1111/j.1365-2311.2003.00551.x.

Heatwole, H. (1996) Energetics of desert invertebrates. Springer Science \& Business Media, Berlin, Germany.

Hijmans, R.J., Cameron, S.E., Parra, J.L., Jones, P.G. \& Jarvis, A. 2005. Very high resolution interpolated climate surfaces for global land areas. International journal of climatology 25:1965-1978 DOI: 10.1002/joc.1276.

Holmgren, M., Scheffer, M., Ezcurra, E., Gutiérrez, J.R. \& Mohren, G.M. 2001. El Niño effects on the dynamics of terrestrial ecosystems. Trends in Ecology \& Evolution 16:89-94 DOI: 10.1016/s0169-5347(00)02052-8.

Holter, P., Scholtz, C. \& Stenseng, L. 2009. Desert detritivory: Nutritional ecology of a dung beetle (Pachysoma glentoni) subsisting on plant litter in arid South African sand dunes. Journal of Arid Environments 73:1090-1094 DOI: http://dx.doi.org/10.1016/j.jaridenv.2009.04.009.

Hortal, J. \& Lobo, J.M. 2005. An ED-based protocol for optimal sampling of biodiversity. Biodiversity and Conservation 14:2913-2947 DOI: 10.1007/s10531-004-0224-z.

Hortal, J., Lobo, J.M. \& Martin-piera, F. 2001. Forecasting insect species richness scores in poorly surveyed territories: the case of the Portuguese dung beetles (Col. Scarabaeinae). Biodiversity \& Conservation 10:1343-1367 DOI: 10.1023/A:1016624500023.

Hortal-Muñoz, J., Martin-Piera, F. \& Lobo, J.M. 2000. Dung beetle geographic diversity variation along a Western Iberian latitudinal transect (Coleoptera: Scarabaeidae). Annals of the Entomological Society of America 93:235-243 DOI: 10.1603/0013-

$$
\text { 8746(2000)093[0235:dbgdva]2.0.co;2. }
$$

Hsieh, T.C., Ma, K.H. \& Chao, A. (2016) iNEXT: iNterpolation and EXTrapolation for species diversity. $R$ package version 2.0.8. $<$ http://chao.stat.nthu.edu.tw/blog/software-download $>$.

Huang, J., Yu, H., Guan, X., Wang, G. \& Guo, R. 2016. Accelerated dryland expansion under climate change. Nature Climate Change 6:166 DOI: 10.1038/nclimate2837.

Hurlbert, A. \& Jetz, W. 2010. More than "More Individuals": The Nonequivalence of Area and Energy in the Scaling of Species Richness. The American Naturalist 176:50-65 DOI: $10.1086 / 650723$.

Hutchinson, G.E. 1959. Homage to Santa Rosalia or Why Are There So Many Kinds of Animals?. The American Naturalist 93:145-159 DOI: 10.1086/282070.

Jones, A., Breuning-Madsen, H., Brossard, M., Dampha, A., Deckers, J., Dewitte, O.and Gallali, T., Hallett, S., Jones, R., Kilasara, M., Le Roux, P., Micheli, E., Montanarella, L., 
704

705

706

707

708

709

710

711

712

713

714

715

716

717

718

719

720

721

722

723

724

725

726

727

728

729

730

731

732

733

734

735

736

737

Spaargaren, O., Thiombiano, L., Van Ranst, E., Yemefack, M. \& Zougmoré, R. (2013) Soil Atlas of Africa. European Commission, Publications Office of the European Union, Luxembourg.

Labidi, I., Errouissi, F. \& Nouira, S. 2012. Spatial and temporal variation in species composition, diversity, and structure of mediterranean dung beetle assemblages (Coleoptera: Scarabaeidae) across a bioclimatic gradient. Environmental Entomology 41:785-801 DOI: 10.1603/en11278.

Legendre, P. \& Gallagher, E.D. 2001. Ecologically meaningful transformations for ordination of species data. Oecologia 129:271-280 DOI: 10.1007/s004420100716.

LeHouérou, H.N. 2001. Biogeography of the arid steppeland north of the Sahara. Journal of Arid Environments 48:103-128 DOI: 10.1006/jare.2000.0679.

Lobo, J., Hortal, J. \& Cabrero-Sañudo, F. 2006. Regional and local influence of grazing activity on the diversity of a semi-arid dung beetle community. Diversity and Distributions 12:111123 DOI: 10.1111/j.1366-9516.2006.00194.x.

Lobo, J.M. 1988. Las trampas pitfall con cebo, sus posibilidades en el estudio de las comunidades coprófagas de Scarabaeoidea (Col.). I. Caracteristicas determinantes de su capacidad de captura. Revue D'Écologie et de Biologiedu Sol 25:77-100.

Lumaret, J.P. (1991). South Temperate Dung Beetles, 95-115. In Dung beetle Ecology. Eds. Hanski, I. \& Cambefort, Y.,, Princeton University Press.

Lumaret, J.P. (1995) Desiccation rate of excrement: a selective pressure on dung beetles (Coleoptera, Scarabaeoidea). Time Scales of Biological Responses to Water Constraints (ed. by Roy, J., Aronson, J. \& di Castri, F.), pp. 105-118. SPB Academic Publishing, Amsterdam, The Netherlands.

Maestre, F.T., Delgado-Baquerizo, M., Jeffries, T.C., Eldridge, D.J., Ochoa, V., Gozalo, B., Quero, J.L., Garcia-Gómez, M., Gallardo, A., Ulrich, W., Bowker, M.A., Arredondo, T., Barraza-Zepeda, C., Bran, D., Florentino, A., Gaitán, J., Gutiérrez, J.R., Huber-Sannwald, E., Jankju, M., Mau, R.L., Miriti, M., Naseri, K., Ospina, A., Stavi, I., Wang, D., Woods, N.N., Yuan, X., Zaady, E. \& Singh, B.K. 2015. Increasing aridity reduces soil microbial diversity and abundance in global drylands. Proceedings of the National Academy of Sciences 112:15684-15689 DOI: 10.1073/pnas.1516684112.

Magurran, A. (2004) Measuring biological diversity. Blackwell Science, Oxford, U.K..

Nichols, E., Gardner, T., Peres, C. \& Spector, S. 2009. Co-declining mammals and dung beetles: An impending ecological cascade. Oikos 118:481-487 DOI: 10.1111/j.16000706.2009.17268.x. 
738 Nichols, E., Uriarte, M., Bunker, D.E., Favila, M.E., Slade, E.M., Vulinec, K., Larsen, T., De739 Mello, F.Z.V., Louzada, J., Naeem, S. \& Spector, S.H. 2013. Trait-dependent response of

740

741

742

743

744

745

746

747

748

749

750

751

752

753

754

755

756

757

758

759

760

761

762

763

764

765

766

767

768

769

770

771 dung beetle populations to tropical forest conversion at local to global scales. Ecology 94:180-189 DOI: 10.1890/12-0251.1.

Noy-Meir, I. 1974. Desert ecosystems: higher trophic levels. Annual Review of Ecology and systematics 5:195-214 DOI: 10.1146/annurev.es.05.110174.001211.

Nunes, C.A., Braga, R.F., Figueira, J.E.C., de Siqueira Neves, F. \& Fernandes, G.W. 2016. Dung Beetles along a Tropical Altitudinal Gradient: Environmental Filtering on Taxonomic and Functional Diversity. PLOS ONE 11:1-16 DOI: 10.1371/journal.pone.0157442.

Oksanen, J., Blanchet, F.G., Friendly, M., Kindt, R., Legendre, P., McGlinn, D., Minchin, P.R., O'Hara, R.B., Simpson, G.L., Solymos, P., Stevens, M.H.H., Szoecs, E. \& Wagner, H. (2016) vegan: Community Ecology Package. $R$ package version 2.4-0. $<$ http://CRAN.Rproject.org $/$ package $=$ vegan $>$.

Pianka, E.R. 1966. Latitudinal gradients in species diversity: a review of concepts. The American Naturalist 100:33-46 DOI: 10.1086/282398.

Pierre, F. 1958. Ecologie et peuplement entomogique des sables vifs du Sahra Nord-Occidental. Publication du Centre de Recherches Sahariennes, série Biologie, $\mathrm{n}^{\circ} 1$. CNRS, Paris.

Polis, G.A. (1991) Desert communities: An overview of patterns and processes. The ecology of desert communities (ed. by Polis, G.A.), pp. 1-26. University of Arizona Press, Tucson, USA.

Polis, G.A., Hurd, S.D., Jackson, C.T. \& Sánchez-Piñero, F. 1997. El Niño effects on the dynamics and control of an island ecosystem in the Gulf of California. Ecology 78:18841897 DOI: $10.2307 / 2266109$.

Rohde, K. 1992. Latitudinal gradients in species diversity: the search for the primary cause. Oikos:514-527 DOI: $10.2307 / 3545569$.

Safriel, U., Adeel, Z., Niemeijer, D., Puigdefabregas, J., White, R., Lal, R., Winslow, M., Ziedler, J., Prince, S., Archer van Garderen, E., King, C., Shapiro, B., Wessels, K., Nielsen, T., Portnov, B., Becker-Reshef, I., Thonnell, J., Lachman, E. \& McNab, D. (2018). 22. In: Scholes, R., Hassan, R. \& Ash, N. (ed. by ), Dryland systems. Ecosystems and Human WellBeing: Current State and Trends, Island Press.

Sánchez-Piñero, F. (1994) Ecología de las comunidades de coleópteros en zonas áridas de la Depresión de Guadix-Baza (sureste de la Península Ibérica). PhD Thesis, University of Granada, Granada, Spain.

Sánchez-Piñero, F. \& Ávila, J.M. 2004. Dung-insect community composition in arid zones of 
772

773

774

775

776

777

778

779

780

781

782

783

784

785

786

787

788

789

790

791

792

793

794

795

796

797

798

799

800

801

802

803

804

805

south-eastern Spain. Journal of Arid Environments 56:303-327 DOI: 10.1016/S01401963(03)00057-0.

Sánchez-Piñero, F., Tinaut, A., Aguirre-Segura, A., Miñano, J., Lencina, J., Ortiz-Sánchez, F. \& Pérez-López, F. 2011. Terrestrial arthropod fauna of arid areas of SE Spain: Diversity, biogeography, and conservation. Journal of Arid Environments 75:1321-1332 DOI: 10.1016/j.jaridenv.2011.06.014.

Sanders, N.J. \& Rahbek, C. 2012. The patterns and causes of elevational diversity gradients. Ecography 35:1-3 DOI: 10.1111/j.1600-0587.2011.07338.x.

Seager, R., Liu, H., Henderson, N., Simpson, I., Kelley, C., Shaw, T., Kushnir, Y. \& Ting, M. 2014. Causes of Increasing Aridification of the Mediterranean Region in Response to Rising Greenhouse Gases. Journal of Climate 27:4655-4676 DOI: 10.1175/jcli-d-13-00446.1.

Seely, M. \& Louw, G. 1980. First approximation of the effects of rainfall on the ecology and energetics of a Namib Desert dune ecosystem. Journal of Arid Environments 3:25-54 DOI: .

Sommer, J.H., Kreft, H., Kier, G., Jetz, W., Mutke, J. \& Barthlott, W. 2010. Projected impacts of climate change on regional capacities for global plant species richness. Proceedings of the Royal Society of London B: Biological Sciences DOI: 10.1098/rspb.2010.0120.

Sowig, P. 1996. Brood care in the dung beetle Onthophagus vacca (Coleoptera: Scarabaeidae): the effect of soil moisture on time budget, nest structure, and reproductive success. Ecography 19:254-258 DOI: 10.1111/j.1600-0587.1996.tb01252.x.

Spector, S. 2006. Scarabaeine dung beetles (Coleoptera: Scarabaeidae: Scarabaeinae): an invertebrate focal taxon for biodiversity research and conservation. The Coleopterists Bulletin 60:71-83 DOI: 10.1649/0010-065x(2006)60[71:sdbcss]2.0.co;2.

Sullivan, G.T., Sullivan, S., Lumaret, J.-P., Baxter, G., Zalucki, M. \& Zeybekoğlu, Ü. 2016. Dung beetles (Coleoptera: Scarabaeidae) utilizing water buffalo dung on the Black Sea coast of Turkey. Turkish Journal of Zoology 40:80-86 DOI: 10.3906/zoo-1412-2.

Tonkin, J.D., Bogan, M.T., Bonada, N., Rios-Touma, B. \& Lytle, D.A. 2017. Seasonality and predictability shape temporal species diversity. Ecology 98:1201-1216 DOI: 10.1002/ecy.1761.

Tovar, M. d. 1.L. (2015) Relación entre características del suelo y grupos funcionales de escarabeidos coprófagos a lo largo de un transecto de aridez en la Región Oriental de Marruecos. MSc at Universidad de Granada, Granada, Spain.

Trabucco, A. \& Zomer, R. 2009. Global aridity index (global-aridity) and global potential evapotranspiration (global-PET) geospatial database. CGIAR Consortium for Spatial Information:Published online, available from the CGIAR-CSI GeoPortal at: 
806

807

808

809

810

811

812

813

814

815

816

817

818

819

820

821

822

823

824

825

826

827

828

829

830

831

832

833

834

835

836

837

838

839

http://www.cgiar-csi.org/ DOI: .

Tshikae, B.P., Davis, A.L. \& Scholtz, C.H. 2013a. Does an aridity and trophic resource gradient drive patterns of dung beetle food selection across the Botswana Kalahari?. Ecological Entomology 38:83-95 DOI: 10.1111/j.1365-2311.2012.01409.x.

Tshikae, B.P., Davis, A.L. \& Scholtz, C.H. 2013b. Dung beetle assemblage structure across the aridity and trophic resource gradient of the Botswana Kalahari: patterns and drivers at regional and local scales. Journal of insect conservation 17:623-636 DOI: 10.1007/s10841013-9547-y.

Tshikae, B.P., Davis, A.L. \& Scholtz, C.H. 2013c. Species richness--Energy relationships and dung beetle diversity across an aridity and trophic resource gradient. Acta oecologica 49:7182 DOI: 10.1016/j.actao.2013.02.011.

Verdú, J. \& Galante, E. 2004. Behavioural and morphological adaptations for a low-quality resource in semi-arid environments: Dung beetles (Coleoptera, Scarabaeoidea) associated with the European rabbit (Oryctolagus cuniculus L.). Journal of Natural History 38:705-715 DOI: 10.1080/0022293021000041707.

Ward, D. (2009) The biology of deserts. Oxford University Press, Oxford, UK.

White, E.P., Ernest, S.K.M., Adler, P.B., Hurlbert, A.H. \& Lyons, S.K. 2010. Integrating spatial and temporal approaches to understanding species richness. Philosophical Transactions of the Royal Society of London B: Biological Sciences 365:3633-3643 DOI: 10.1098/rstb.2010.0280.

Wiens, J.J., Kozak, K.H. \& Silva, N. 2013. Diversity and niche evolution along aridity gradients in North American lizards (Phrynosomatidae). Evolution 67:1715-1728 DOI: 10.1111/evo.12053.

Willig, M.R., Kaufman, D.M. \& Stevens, R.D. 2003. Latitudinal gradients of biodiversity: pattern, process, scale, and synthesis. Annual Review of Ecology, Evolution, and Systematics 34:273-309 DOI: 10.1146/annurev.ecolsys.34.012103.144032.

Willis, K.J. \& Whittaker, R.J. 2002. Species Diversity--Scale Matters. Science 295:1245-1248 DOI: $10.1126 /$ science. 1067335.

Wright, D.H. 1983. Species-Energy Theory: An Extension of Species-Area Theory. Oikos 41:496-506 DOI: 10.2307/3544109.

Zeppel, M.J., Wilks, J.V., Lewis, J.D. \& others 2014. Impacts of extreme precipitation and seasonal changes in precipitation on plants. Biogeosciences 11:3083-3093 DOI: 10.5194/bg11-3083-2014. 


\section{Table $\mathbf{1}$ (on next page)}

Multivariate GLM on the effects of temporal (seasonal and interanual) variations of aridity over species richness, abundance and evenness.

Significance levels after Bonferroni correction: ${ }^{* * * *} p<0.0001 ; * * * p<0.0003 ; * * p<0.003$;

$* p<0.016$. 
1

\begin{tabular}{llll} 
Effect & Richness & $\log 10$ Abundance & $\log 10$ Evenness \\
& $\mathrm{F}(1,35)$ & $\mathrm{F}(1,35)$ & $\mathrm{F}(1,35)$ \\
\hline Aridity & $15.17^{* * *}$ & 6.39 & 1.43 \\
\hline Season*Aridity & $67.07^{* * *}$ & 2.72 & $38.75 * * *$ \\
\hline Year*Aridity & $7.57^{*}$ & 2.48 & 5.16 \\
\hline Year*Season*Aridity & 1.11 & 0.02 & 4.27 \\
\hline
\end{tabular}

2 


\section{Table 2 (on next page)}

Variation of seasonal (wet-dry) and interannual (2013-2014) dissimilarity for species occurence (Sørensen) and abundances (Bray-Curtis) in relation to aridity and its interaction with year and season.

Sørensen dissimilarity for interannual comparison and Bray-Curtis dissimilarity for both seasonal and interannual comparisons were arcsin transformed. Statistical significance levels after Bonferroni correction: ${ }^{*} p<0.0125 ;{ }^{* *} p<0.0025 ;{ }^{* * *} p<0.00025$. 
1

\begin{tabular}{|c|c|c|c|c|}
\hline & & Sørensen & & Bray-Curtiss \\
\hline Effect & Coefficient \pm S.E. & $\mathrm{F}(1,17)$ & Coefficient \pm S.E. & $\mathrm{F}(1,17)$ \\
\hline \multicolumn{5}{|l|}{ Seasonal } \\
\hline Aridity & $-1.974 \pm 0.406$ & $23.63 * * *$ & $-3.473 \pm 0.458$ & $57.58 * * *$ \\
\hline Year*Aridity & $0.019 \pm 0.032$ & 0.33 & $0.064 \pm 0.036$ & 3.14 \\
\hline \multicolumn{5}{|l|}{ Interannual } \\
\hline Aridity & $0.184 \pm 0.529$ & 0.12 & $1.468 \pm 0.424$ & $12.00 * *$ \\
\hline Season*Aridity & $0.008 \pm 0.042$ & 0.04 & $0.109 \pm 0.034$ & $10.49 * *$ \\
\hline
\end{tabular}

2 


\section{Table 3 (on next page)}

Spearman rank correlation coefficients for the relationship between pairwise difference in aridity between sites and the components of the partitioning of Beta and Bray-Curtis dissimilarities.

We used beta diversity (turnover and nestedness components of Sørensen index) and abundance-based dissimilarity (balanced and gradient components of Bray-Curtis index) for the different surveys. Significance values after Bonferroni correction: $\mathrm{ms}=$ marginally significant; $* p<0.003 ; * * p<0.0006$; ** $p<0.00006$. 
1

\begin{tabular}{lllllll}
\hline \multirow{2}{*}{ Year } & \multirow{2}{*}{ Season } & \multicolumn{2}{c}{ Sørensen } & & \multicolumn{2}{c}{ Bray-Curtis } \\
\cline { 3 - 4 } \cline { 5 - 6 } \cline { 5 - 6 } 2013 & Wet & 0.429 & -0.022 & & $0.593 * * *$ & -0.135 \\
& Dry & $0.493 * *$ & -0.210 & & $0.487 *$ & -0.331 \\
\multirow{2}{*}{2014} & Wet & $0.536 * *$ & -0.208 & & $0.683 * * *$ & -0.402 \\
& Dry & $0.590 * * *$ & 0.116 & $0.479 *$ & -0.308 \\
\hline
\end{tabular}

2 


\section{Figure 1}

Map of the ca. $400 \mathrm{Km}$ transect from a semiarid zone (mor.10, Mediterranean coast) to the desert area (mor.1, Sahara desert).

The map is constructed by overlapping an aridity layer (Trabucco et al., 2009) depicted in green-yellow-brown shading and an altitude layer (Hijmans et al., 2005) converted into elevation isolines (spaced 200 altitudinal meters). 


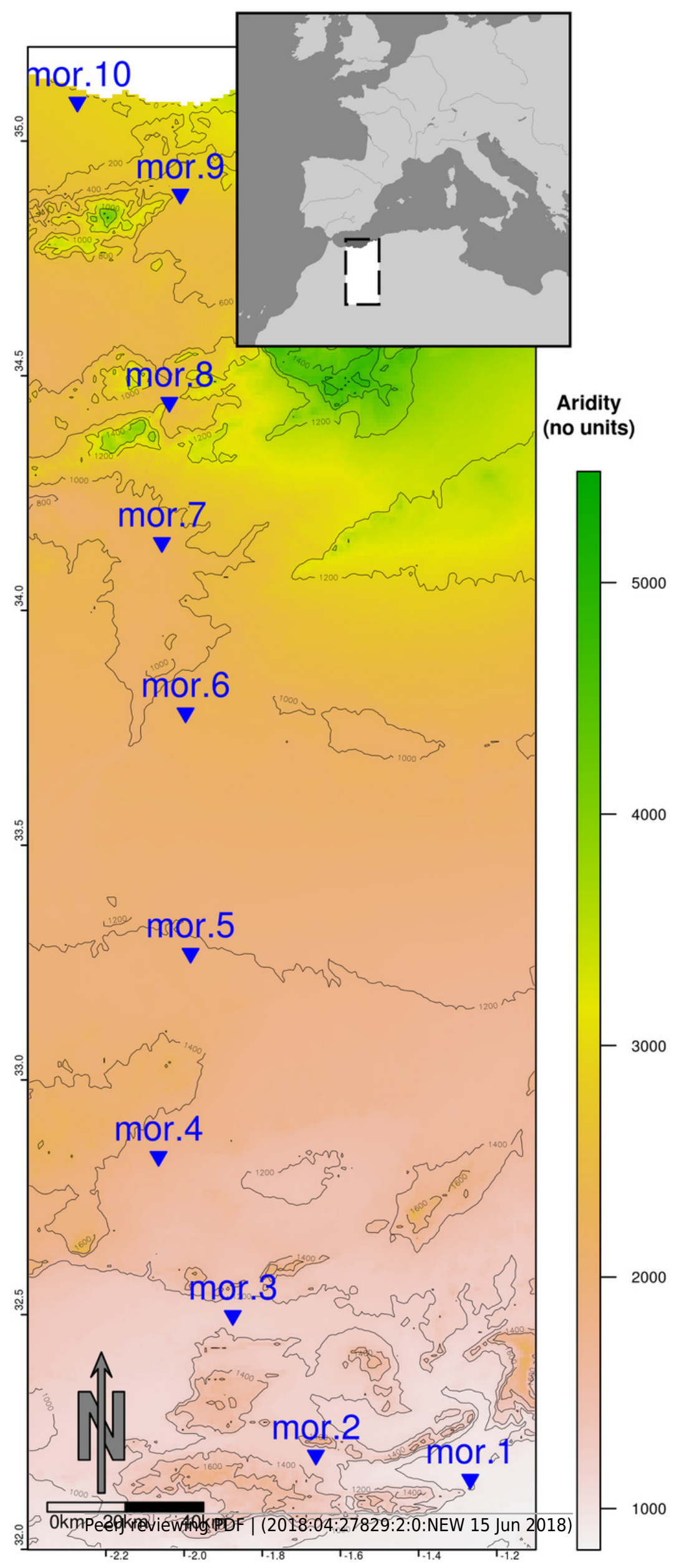




\section{Figure 2}

Variations in dung beetle community descriptors along an aridity gradient from a semiarid zone to the Sahara desert during the wet and dry seasons in 2013 and 2014.

Variations in species (A, D) richness, (B, E) log abundance and (C, F) evenness along an aridity gradient from a semiarid zone ( $300 \mathrm{~mm}$ mean annual rainfall) to the Sahara desert (100 mm) during the wet (April, blue lines) and dry (September, red lines) seasons in 2013 (A-C) and 2014 (D-F). The straight lines in the figures for species richness show the regression lines for the wet and dry season each year. Abundance and evenness did not show either linear nor unimodal fits to aridity. The range of $Y$ axis was standardized to allow easier comparison between years. 

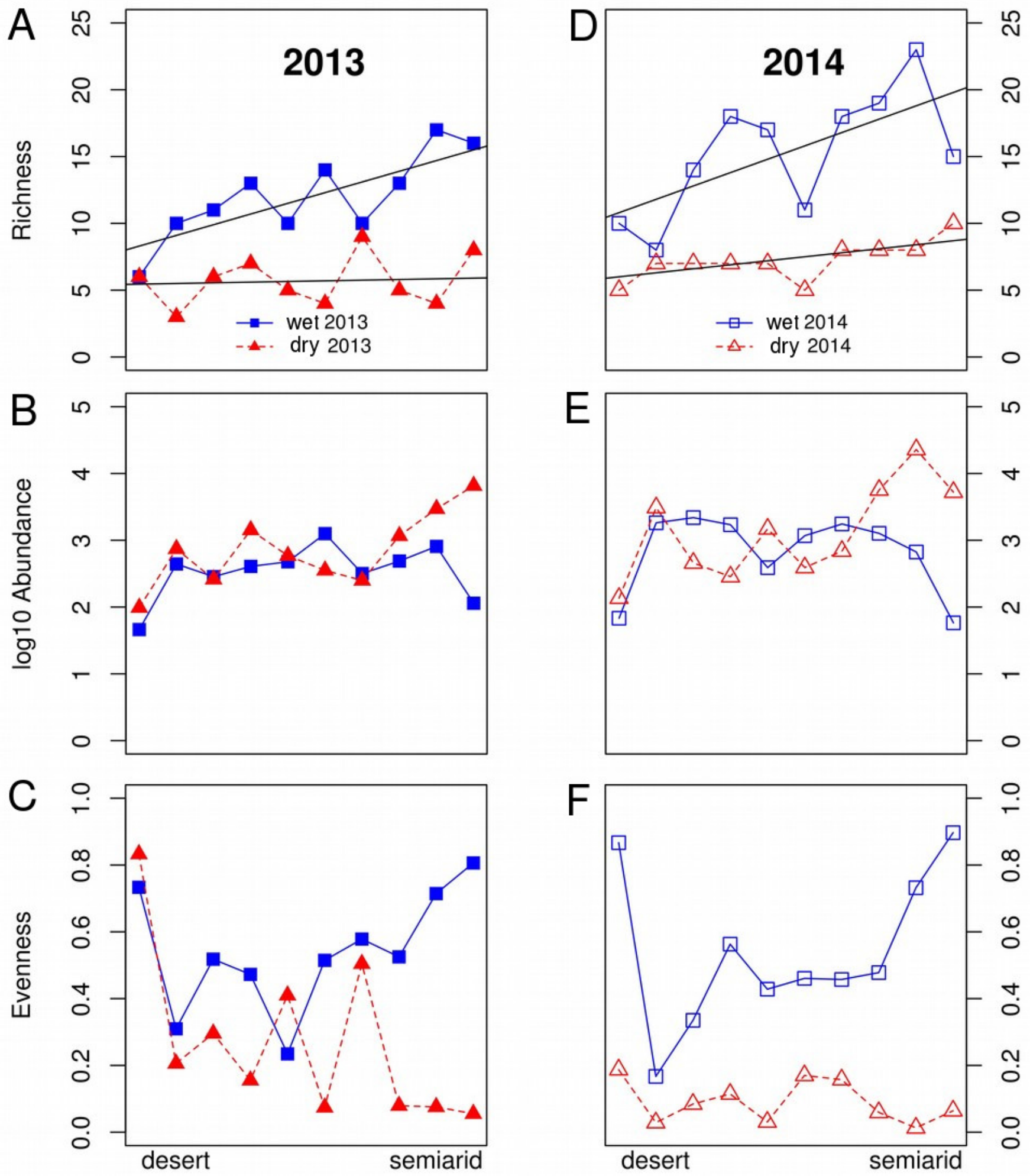
Figure 3

Non-metric multi-dimensional scaling (NMDS) ordination (stress $=0.12$ ) of community composition for the different sites in the wet and the dry season of the two sampled years (2013 and 2014).

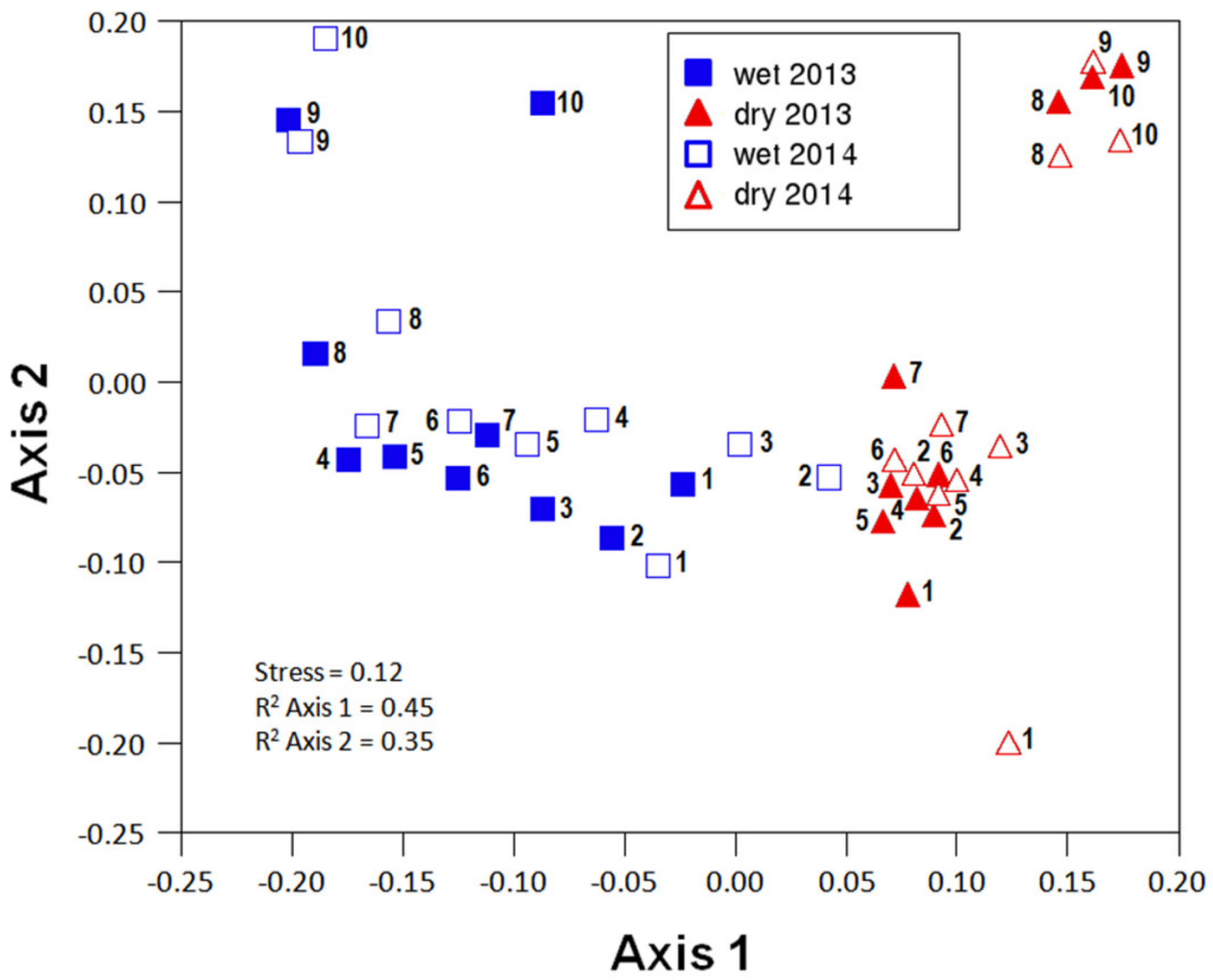




\section{Figure 4}

Temporal beta diversity (Sørensen coefficient) and Bray-Curtis dissimilarities of dung beetle communities along the aridity gradient.

(A-B) Seasonal beta diversity and Bray-Curtis dissimilarities respectively; each bar compares communities for the same site in the wet and the dry seasons. (C-D) Interannual beta diversity and Bray-Curtis dissimilarities respectively; each bar compares communities for the same site in the two years included in this study. Beta diversity is partitioned in two components: beta turnover (dark colours) and beta nestedness (light colours). Bray-Curtis dissimilarities are also partitioned in two components: BC gradient (dark colours) and BC balanced (light colours). The range of $\mathrm{Y}$ axis (showing all possible variation of beta diversity or $\mathrm{BC}, 0-1$ ) was standardized in all plots to allow easier comparison.

\section{Seasonal variation}

(temporal fine-scale)

-Beta tunover $\square$ Beta nestedness

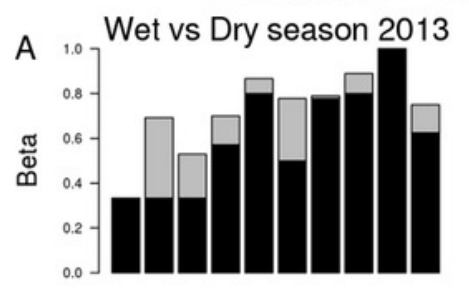

$\square \mathrm{BC}$ gradient $\square \mathrm{BC}$ balanced

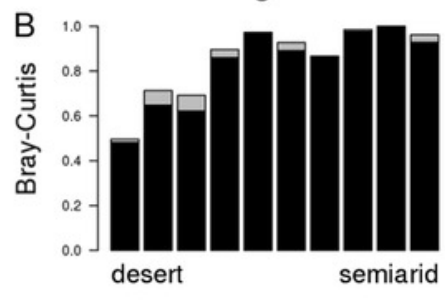

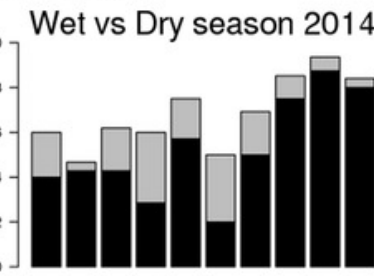

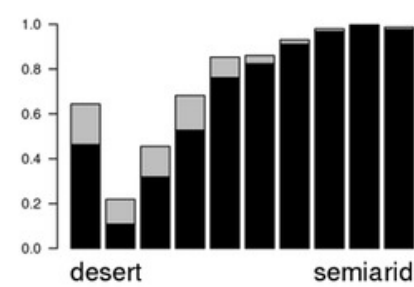

Interannual variation

(temporal broad-scale)

-Beta tunover $\square$ Beta nestedness
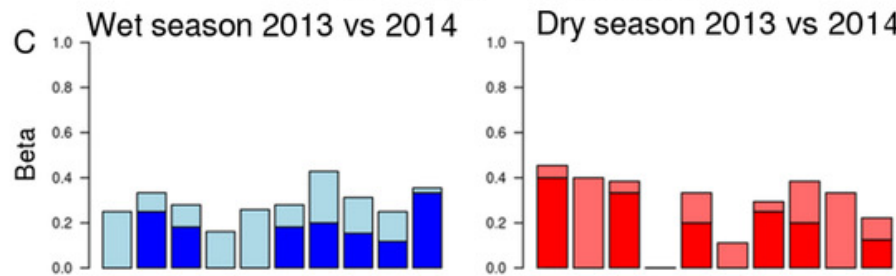

- $\mathrm{BC}$ gradient $\quad \square \mathrm{BC}$ balanced

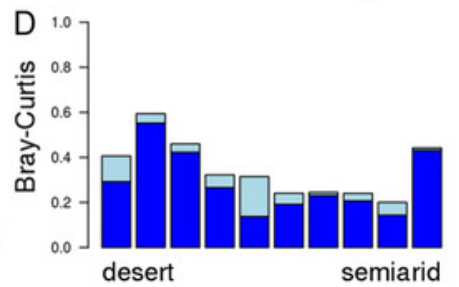




\section{Figure 5}

Multiple site dissimilarity of dung beetle communities along the aridity gradient based on species occurrence (Sørensen) and considering species abundances (Bray-Curtis).

Multiple site dissimilarity partitioning into turnover/nestedness or balanced/gradient components of dung beetle communities along the aridity gradient for the different seasons and years sampled based on (A) species occurrence (Sørensen) and (B) considering species abundances (Bray-Curtis). 


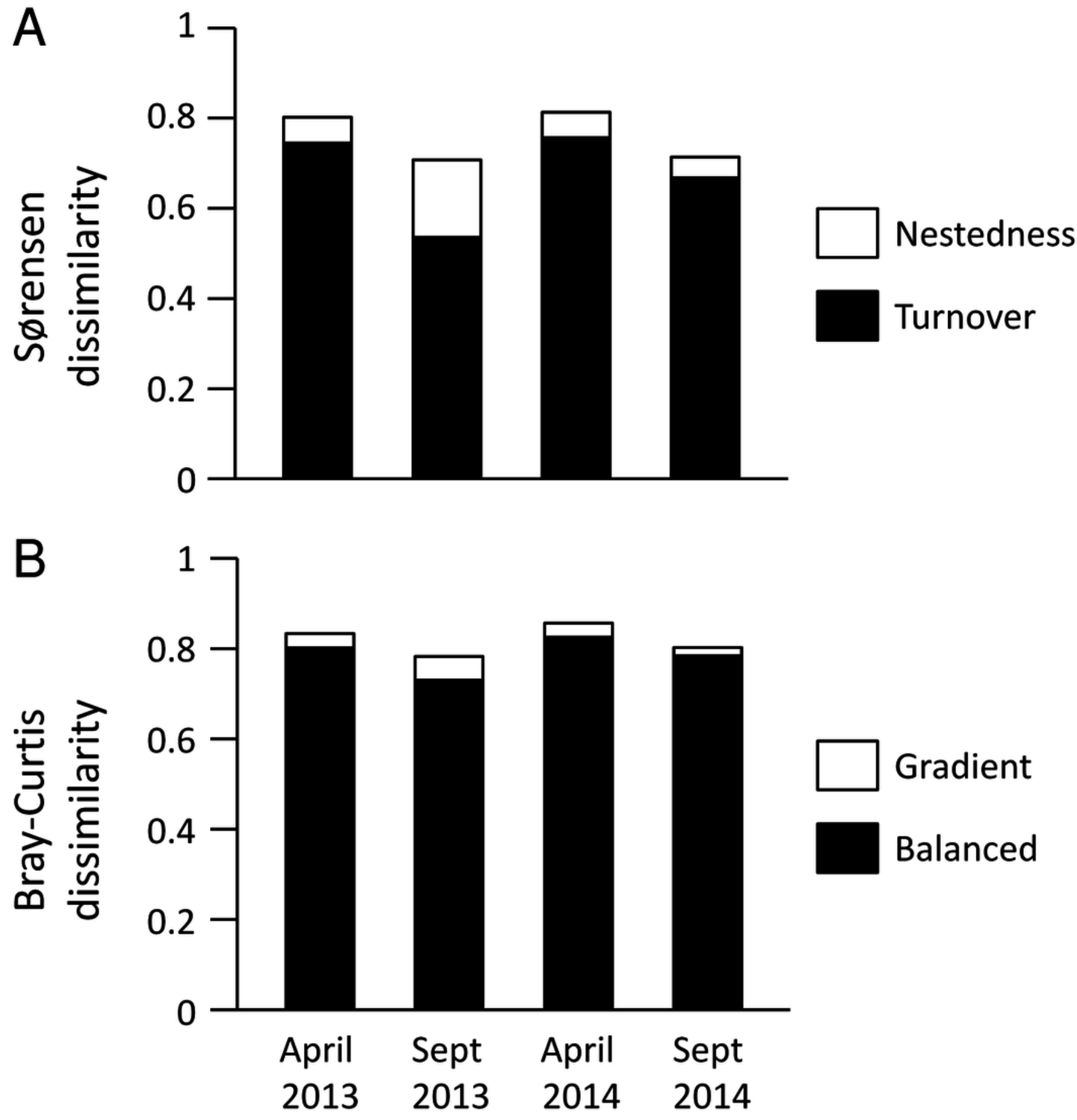




\section{Figure 6}

Distribution of standardized coefficients of PLS-GLR models for richness and abundance using all available environmental variables.

Boxplots show standardized coefficients of PLS-GLR models for species richness in the wet season (A) and abundance in the dry season (B) of dung beetle communities along an aridity gradient from a semiarid zone (300 $\mathrm{mm}$ mean annual rainfall) to the Sahara desert (100 $\mathrm{mm}$ ). Standardized coefficients were obtained by bootstrap (1000 iterations) to identify the importance of predictor variables in the models. Significant predictor variables differ from 0 . 

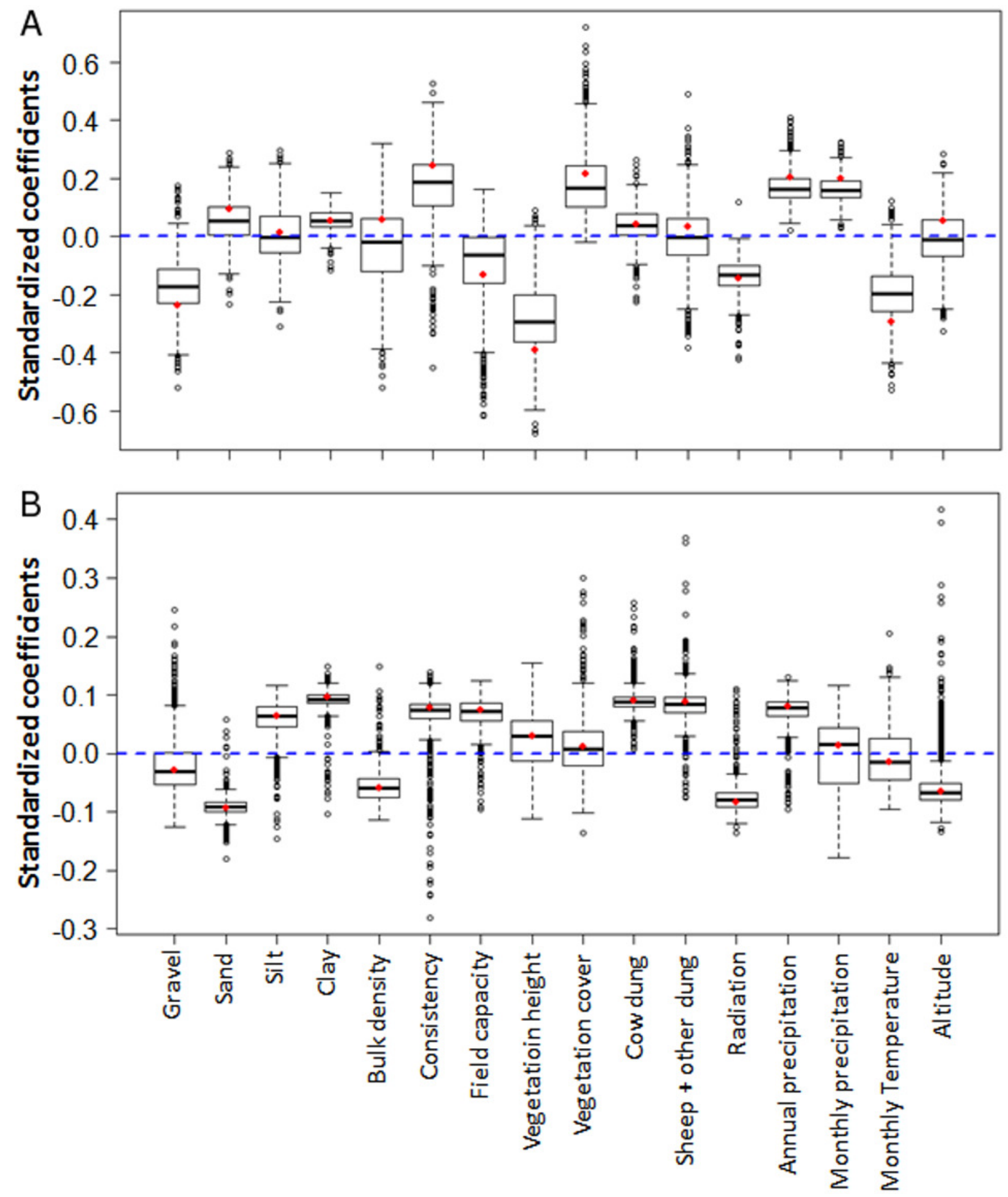